\title{
On Efficient Monitoring of Weibull Lifetimes Using Censored Median Hybrid DEWMA Chart
}

\author{
Syed Muhammad Muslim Raza $\mathbb{D D}^{1}$ Sajid Ali $\mathbb{D}^{2},{ }^{2}$ Ismail Shah $\mathbb{D D}^{2}$ Lichen Wang ${ }^{2}{ }^{3}$ \\ and Zhen Yue $\mathbb{i D}^{3}$ \\ ${ }^{1}$ Department of Quantitative Methods, School of Business and Economics, University of Management and Technology, \\ Lahore, Pakistan \\ ${ }^{2}$ Department of Statistics, Quaid-i-Azam University, Islamabad 45320, Pakistan \\ ${ }^{3}$ College of Life Sciences, Linyi University, Linyi, Shandong 276000, China
}

Correspondence should be addressed to Lichen Wang; wanglichen@lyu.edu.cn and Zhen Yue; yuezhen571@163.com

Received 10 March 2020; Revised 26 April 2020; Accepted 13 May 2020; Published 13 June 2020

Academic Editor: Zhile Yang

Copyright (C) 2020 Syed Muhammad Muslim Raza et al. This is an open access article distributed under the Creative Commons Attribution License, which permits unrestricted use, distribution, and reproduction in any medium, provided the original work is properly cited.

\begin{abstract}
A control chart named as the hybrid double exponentially weighted moving average (HDEWMA) to monitor the mean of Weibull distribution in the presence of type-I censored data is proposed in this study. In particular, the focus of this study is to use the conditional median (CM) for the imputation of censored observations. The control chart performance is assessed by the average run length (ARL). A comparison between CM-DEWMA control chart and CM-based HDEWMA control chart is also presented in this article. Assuming different shift sizes and censoring rates, it is observed that the proposed control chart outperforms the CM-DEWMA chart. The effect of estimation, particularly the scale parameter estimation, on ARL is also a part of this study. Finally, a practical example is provided to understand the application and to investigate the performance of the proposal in practical scenarios.
\end{abstract}

\section{Introduction}

In practice, we often deal with the detection of assignable causes in the lifetime data, especially in medical and industrial experiments. However, the limitations of time and of cost lead to limited data collection often called censored data. To monitor such experiments for possible presence of assignable causes of variation and to improve process quality, the traditional control charts, e.g., Shewhart charts, have very poor performance. In fact, these charts, generally, do not react timely and produce inflated false alarm rates. Consequently, the traditional charts have low discriminatory monitoring power for censored data. To overcome these undesirable properties of the monitoring schemes for censored data, Steiner and Mackay [1] introduced a one-sided charting procedure based on the conditional expected value $(\mathrm{CEV})$. The authors showed by an empirical study that the proposal allows rapid detection of process deterioration for monitoring highly censored data.
Different types of censoring schemes exist in statistics, for example, the type-I, type-II, interval, progressive, etc., [2], although in the industry, type-I censoring is one of the most commonly used schemes [3]. In this scheme, the lifetime of the units within the interval $[0, T]$ is observed for a fixed $T$ while the observations having lifetime greater than $T$ are declared as the censored observations. In other words, the exact failure time of the observation greater than $T$ cannot be observed.

Due to the practical significance of censored data in different fields, numerous studies have been done to propose efficient monitoring strategies. The first CEV-based Shewhart type control chart was introduced by Steiner and Mackay [4]. In continuation of the previous study, Steiner and Mackay [5] noticed that in many applications, highly censored data are collected under repetitive life testing environments. The authors showed that the CEV-based charting schemes are very effective in such situations. Later, Zhang and Chen [6] extended the idea of Steiner and 
Mackay $[1,4,5]$ by introducing lower and upper-sided CEVbased exponentially weighted moving average (EWMA) control charts. Following the CEV idea, Lu and Tsai [7] and Tsai and Lin [8] proposed EWMA charts for monitoring type-I censored data assuming the gamma and Gompertz models, respectively. For more recent studies based on the CEV idea, we refer to Raza et al. [9, 10], Zhang et al. [11], and references cited therein. It is worth mentioning that most of the lifetime distributions are skewed, and hence CEV approach may not be appropriate. Thus, contrary to the existing approaches, Raza and Siddique [12] proposed conditional median- (CM-) based Shewhart chart. Using Monte Carlo (MC) simulations, the authors showed that the chart constructed using the CM approach outperforms the CEV-based chart. Apart from type-I censoring, the control charts to monitor type-II censored data are also available in the literature [13-15]; however, due to the practical applications, the main focus of this study is to monitor type-I censored data.

Before proceeding further, it is important to differentiate among the $\mathrm{CEV}$, the CM, and imputation approaches. Methodologically, all the three approaches are the same; however, practically the CEV and CM replace the censored observations with the conditional mean and conditional median, respectively. On the contrary, the imputation methods are used to substitute the missing observations [16-18]. Thus, all of them are used to replace censored/ missing data that eventually improve the estimation of unknown parameters.

The aim of this article is to introduce a hybrid CM-based double exponentially weighted moving average (DEWMA) control chart for monitoring the type-I censored Weibull data. In addition, a performance comparison of the CMbased DEWMA with the proposal is also presented in this study. For assessing the effect of estimation method on the ARL, the maximum likelihood estimation (MLE) is used. To the best of our knowledge, it is to be noted that the existing hybrid EWMA control charts [19-21] do not deal with censored data and this is the first proposal that discusses hybrid DEWMA control chart for censored data.

The remainder of the article is organized as follows. CM for the Weibull distribution is derived in Section 2 while scale parameter estimation is also discussed in the same section. The CM-based hybrid DEWMA charts are presented in Section 3, whereas the performance of the chart is discussed and compared with the CM-DEWMA chart in Section 4. Furthermore, the parameter estimation impact is also discussed in the same section. A real-life application is provided in Section 5 while Section 6 provides the concluding critiques.

\section{CM for the Weibull Distribution}

Let a lifetime test be conducted where $X$ denotes the lifetime of a product. Furthermore, assume that $X$ follows a Weibull distribution, which is selected because of its applications in reliability and other engineering applications [2]. The probability density function of a Weibull random variable $X$ can be written as $f(x, \alpha, \beta)=\left(\beta / \alpha^{\beta}\right) x^{\beta-1} \exp \left(-[x / \alpha]^{\beta}\right)$ where $x>0$ and $\alpha$ and $\beta$ are the scale and the shape parameter of the distribution. Further, assume type-I censoring scheme for the lifetimes $X_{i 1}, X_{i 2}, \ldots \ldots, X_{\mathrm{in}}, i=1,2, \ldots, m$, where $m$ represents the subgroup number and $n$ is the sample size. We define the censoring rate as $P_{c}=\exp \left(-[C / \alpha]^{\beta}\right)$, where $\mathrm{C}$ denotes the censoring time.

In this study, as the aim is to monitor the mean level, i.e., $\mu=E(x)=\int_{0}^{\infty} x f(x) \mathrm{d} x=\alpha \Gamma(1+1 / \beta)$, of the censored Weibull lifetimes, the in-control mean lifetime is $\mu_{o}=\alpha_{0} \Gamma(1+1 / \beta)$. Using the knowledge of the shape parameter and of the in-control mean, one can determine the scale parameter [22]. For example, if the shape parameter and mean levels are fixed, say $\beta_{0}=2$ and $\mu=10$, then the scale parameter can be computed as $\alpha=\mu \Gamma\left(1+\left(1 / \beta_{0}\right)\right)^{-1}=10 * \Gamma(1+0.5)^{-1}=11.285$. Now, suppose the shape parameter is known and only the scale parameter is the parameter of interest in a process monitoring problem. Thus, to monitor the mean level, there can be two cases, i.e., when $\alpha$ is known and when it is unknown. This study presents control charts for both cases. For the case of unknown $\alpha$, the maximum likelihood estimation (MLE) method is used.

As the EWMA control chart [23] is known to be a memory type control chart, it uses not only the present information but also the past; therefore, it is more efficient to detect small and moderate shifts than the memoryless charts which are generally used to detect large shifts. $\mathrm{CM}=\mathrm{cm}$ for the Weibull distribution is derived as

$$
\int_{c}^{\mathrm{cm}} x^{\beta-1} \exp \left[\left(-\frac{x}{\alpha}\right)^{\beta}\right] \mathrm{d} x=\frac{\alpha^{\beta} \exp \left(-D_{c}\right)}{2 \beta} .
$$

By solving the above equation, one can get the following expression:

$$
\mathrm{cm}=\left[\frac{-\alpha_{0}^{\beta} \ln \left(2-\exp \left(-D_{c}\right)\right)}{2}\right]^{1 / \beta_{0}}
$$

where $D_{c}=\left(C / \alpha_{0}\right)^{\beta_{0}}, \Gamma(x, a)=\int_{y=0}^{x} y^{a-1} \exp (-y) \mathrm{d} y$, and $\alpha_{0}$ and $\beta_{0}$ are the in-control values of $\alpha$ and $\beta$, respectively.

2.1. Estimation of $\alpha$. Generally, parameters are assumed fixed and known; however, there is no justification of this assumption in practice. To this end, phase-I dataset is used to estimate the unknown parameter. In this study, we fix the shape parameter of the Weibull distribution and estimate the scale parameter by the maximum likelihood estimation (MLE) method. The likelihood function for the censored data is given as [2]

$$
L(\alpha \mid \beta, x)=\prod_{i=1}^{n}\left[\frac{\beta}{\alpha^{\beta}} x^{\beta-1} \exp \left(-[x / \alpha]^{\beta}\right)\right]^{\phi_{i}}\left[\exp \left(-[C / \alpha]^{\beta}\right)\right]^{\left(1-\phi_{i}\right)} \text {. }
$$

The MLE of $\alpha$, assuming fixed $\beta$, is calculated by finding the partial derivative of equation (3) with respect to the unknown parameter and equating it to zero, i.e., $\partial L / \partial \alpha=0$. Further, it is necessary to have $\partial^{2} L / \partial \alpha^{2}<0$. The simplified form of the MLE for $\alpha$ is given as: 
$\hat{\alpha}_{\mathrm{MLE}}=(1 / k)\left[\sum_{i=1}^{k} \phi_{i}\left(X_{i}\right)^{\beta_{0}}+(n-k) C^{\beta_{0}}\right]^{1 / \beta_{0}}$, where $k$ denotes the number of censored units per subgroup, $n$ is the number of sampling units, and $X_{i}(i=1,2,3, \ldots, n)$ denote the lifetimes from the Weibull distribution which can only be observed if $x_{i}<C$. Thus, $\phi_{i}=1$ if $x_{i} \leq C$, and $\phi_{i}=0$ if $x_{i}>C$ with the property $\sum_{i=1}^{n} \phi_{i}=k$.

\section{CM-Based Hybrid DEWMA Chart}

Here, we introduce the CM-based hybrid DEWMA (CMHDEWMA) chart but before discussing its design structure, let us recall the layout of the EWMA and the DEWMA charts using CM approach. To this end, transform the lifetimes $X_{\mathrm{i} 1}$, $X_{i 2} \ldots, X_{\text {in }}$ into $G_{i j}$ as follows:

$$
G_{i j}=\left\{\begin{array}{ll}
X_{i j}, & \text { if } X_{i j} \leq C, \\
C M\left(X_{i j}\right), & \text { if } X_{i j}>C,
\end{array} \quad \forall j=1,2, \ldots, n \text { and } i=1,2, \ldots, m .\right.
$$

Then, calculate the CMEWMA statistics as

$$
\mathrm{EWC}_{i(\mathrm{CM})}=\frac{\max \left\{(1-\gamma) \mathrm{EWC}_{i-1(\mathrm{CM})}+\gamma \bar{G}_{i}^{\mathrm{CM}}, d_{o}\right\}}{\min \left\{(1-\gamma) \mathrm{EWC}_{i-1(\mathrm{CM})}+\gamma \bar{G}_{i}^{\mathrm{CM}}, d_{o}\right\}},
$$

with

$$
\begin{aligned}
i \geq 0, \bar{G}_{i} & =\left(\frac{\sum_{j=1}^{n} G_{i j}}{n}\right), \\
\mathrm{EWC}_{0} & =d_{0}
\end{aligned}
$$

where $d_{o}$ denotes the in-control mean and $0<\gamma<1$ is the smoothing parameter. Similarly, the CM-DEWMA statistic is defined as

$$
\mathrm{DEC}_{i(\mathrm{CM})}=\frac{\max \left\{(1-\lambda) \mathrm{DEC}_{i-1(\mathrm{CM})}+\lambda \mathrm{EWC}_{i(\mathrm{CM})}, k_{o}\right\}}{\min \left\{(1-\lambda) \mathrm{DEC}_{i-1(\mathrm{CM})}+\lambda \mathrm{EWC}_{i(\mathrm{CM})}, k_{o}\right\}},
$$

with $i \geq 0$ and $\mathrm{DEC}_{0}=k_{0}$, where $k_{0}$ refers to the in-control mean and DEC denotes the double EWMA charting statistic. For signaling, plot $\mathrm{EWC}_{i(\mathrm{CM})}\left(\mathrm{DEC}_{i(\mathrm{CM})}\right)$ against the $\mathrm{UCL}_{\mathrm{EWC}(\mathrm{CM})}\left(\mathrm{UCL}_{\mathrm{DEC}(\mathrm{CM})}\right)$ and declare the process as incontrol (IC) when the monitoring statistic falls below the upper control limit (UCL); otherwise, it is declared as out-ofcontrol (OCC). If the process is out-of-control, the identification process should be initiated for the detection of a possible assignable cause. As discussed by Polunchenko et al. [24], the most accepted choices of $\gamma$ and $\lambda$ range from 0.05 to 0.25 for small shift detection while they range from 0.25 to 0.4 for moderate shifts. To compare the performance of the proposed chart with the CM-based DEWMA control chart, the procedure is adopted as discussed in Raza et al. [10, 25]. As the $\mathrm{EWC}_{i(\mathrm{CM})}$ statistic increases for both shifts, i.e., upward and downward shifts in the process mean [10], only the upper control limit, say, $\mathrm{UCL}_{\mathrm{EWC}(\mathrm{CM})}$ is required. To calculate the UCL, it is suggested to compute the EWC and DEC statistics for the given $m$ and $n$ using in-control data and obtain the $(1-p)$ th quantile point, where $p$ is prespecified. This will result in UCL for the CM-EWMA or CM-DEWMA chart. For monitoring, plot $\mathrm{EWC}_{i(\mathrm{CM})}$ against the $\mathrm{UCL}_{\mathrm{EWC}(\mathrm{CM})}$ as long as the monitoring statistic falls below the upper control limit; otherwise, declare the process to be out-of-control. In the case of an out-of-control signal, an engineer should inspect the process for the removal of the assignable cause.

Next, the hybrid DEWMA control chart for monitoring the censored data is discussed. To this end, let the smoothing constants $\lambda_{1}, \lambda_{2}, \lambda_{3} \in[0,1]$ and define the following two sequences $E_{1}, E_{2}, \ldots$ and $\mathrm{HE}_{1}, \mathrm{HE}_{2}, \ldots$ as

$$
\begin{array}{r}
E_{i}^{\mathrm{CM}}=\lambda_{1} \bar{G}_{i}^{\mathrm{CM}}+\left(1-\lambda_{1}\right) E_{i-1(\mathrm{CM})}, \\
\mathrm{HE}_{i}^{C M}=\lambda_{2} E_{i}^{C M}+\left(1-\lambda_{2}\right) \mathrm{HE}_{i-1(\mathrm{CM})} .
\end{array}
$$

The plotting statistic of CM-HEWMA is then calculated as

$$
\mathrm{EWC}_{i(\mathrm{CM})}=\frac{\max \left\{\mathrm{HE}_{i}^{\mathrm{CM}}, \text { intial value }\right\}}{\min \left\{\mathrm{HE}_{i}^{\mathrm{CM}}, \text { intial value }\right\}} .
$$

Finally, the CM hybrid DEWMA monitoring statistic is defined as

$$
\mathrm{DWC}_{i(\mathrm{CM})}=\frac{\max \left\{\mathrm{DHE}_{i}^{\mathrm{CM}}, \text { intial value }\right\}}{\min \left\{\mathrm{DHE}_{i}^{\mathrm{CM}}, \text { intial value }\right\}}
$$

where $\mathrm{DHE}_{i}^{\mathrm{CM}}=\lambda_{3} \mathrm{HE}_{i}^{\mathrm{CM}}+\left(1-\lambda_{3}\right) \mathrm{DHE}_{i-1(\mathrm{CM})}$.

The monitoring procedure of HDEWMA and HEWMA charts is the same as discussed for the CM-EWMA and CMDEWMA charts. To calculate the UCL of the CMHDEWMA and CM-DEWMA charts, an algorithm is discussed in the next section. Furthermore, a performance comparison of CM-HDEWMA and CM-DEWMA charts assuming known and estimated parameter cases under different censoring rates is also presented.

\section{Performance Evaluation of the Chart}

To assess the performance of CM-HDEWMA and CMDEWMA charts considering known and estimated parameter cases under different censoring rate, the average run length (ARL) performance assessment measure is used in this study.

Assuming fixed $\beta=2$, the censoring time for different choices of the scale parameter corresponding to different censoring rates is computed in Table 1. It is noticed from the table that for a given $\alpha$, the censoring time decreases as the censoring rate increases. For instance, consider the case of $P_{C}=0.2$ and $P_{C}=0.7$ for $\alpha=0.7$. The corresponding censoring times are 0.888 and 0.4181 , respectively. Further, assuming a fixed censoring rate, the censoring time increases with the increase of $\alpha$, e.g., when $P_{C}=0.2$, the censoring times are 0.2537 and 0.8880 for $\alpha=0.2$ and 0.7 , respectively. The results are quite realistic since for type-I censoring, censoring rate can only be increased by decreasing censoring time and vice versa. In addition, for fixed censoring rate, censoring time increases by increasing the scale parameter of the Weibull distribution as the events occur more frequently when the scale parameter increases.

Next, to evaluate the impact of estimation, the $\mathrm{UCL}_{\text {CMHDEWMA }}$ for different choices of $\mathrm{ARL}_{0}, m, n$, and $P_{c}$, is 
TABle 1: Censoring times $C$.

\begin{tabular}{|c|c|c|c|c|c|c|}
\hline \multirow{2}{*}{$P_{c}$} & \multicolumn{6}{|c|}{$\alpha$} \\
\hline & 0.1 & 0.2 & 0.3 & 0.5 & 0.7 & 0.9 \\
\hline 0.1 & 0.151743 & 0.303485 & 0.455228 & 0.758714 & 1.062199 & 1.365684 \\
\hline 0.15 & 0.137736 & 0.275472 & 0.413208 & 0.68868 & 0.964152 & 1.239624 \\
\hline 0.2 & 0.126864 & 0.253727 & 0.380591 & 0.634318 & 0.888045 & 1.141773 \\
\hline 0.25 & 0.117741 & 0.235482 & 0.353223 & 0.588705 & 0.824187 & 1.059669 \\
\hline 0.3 & 0.109726 & 0.219451 & 0.329177 & 0.548628 & 0.76808 & 0.987531 \\
\hline 0.35 & 0.102461 & 0.204922 & 0.307382 & 0.512304 & 0.717226 & 0.922147 \\
\hline 0.4 & 0.095723 & 0.191446 & 0.287169 & 0.478615 & 0.670062 & 0.861508 \\
\hline 0.45 & 0.089359 & 0.178719 & 0.268078 & 0.446796 & 0.625515 & 0.804233 \\
\hline 0.5 & 0.083255 & 0.166511 & 0.249766 & 0.416277 & 0.582788 & 0.749299 \\
\hline 0.55 & 0.07732 & 0.15464 & 0.23196 & 0.3866 & 0.541239 & 0.695879 \\
\hline 0.6 & 0.071472 & 0.142944 & 0.214416 & 0.35736 & 0.500304 & 0.643249 \\
\hline 0.65 & 0.065634 & 0.131268 & 0.196902 & 0.32817 & 0.459438 & 0.590706 \\
\hline 0.7 & 0.059722 & 0.119445 & 0.179167 & 0.298611 & 0.418056 & 0.537505 \\
\hline 0.75 & 0.053636 & 0.107272 & 0.160908 & 0.268181 & 0.375452 & 0.482724 \\
\hline 0.8 & 0.047238 & 0.094476 & 0.141714 & 0.236194 & 0.330667 & 0.425143 \\
\hline 0.85 & 0.040314 & 0.080627 & 0.120941 & 0.201568 & 0.282195 & 0.362823 \\
\hline
\end{tabular}

computed and tabulated in Table 2. It is worth mentioning that in Table 2, $\alpha=0.5$ is assumed as the nominal value of the scale parameter for $n=3$ and $n=7$, respectively. It can be seen clearly from the table that the estimation of parameter significantly affects the UCL of the chart. This comment is not specific for a small censoring rate but equally valid for a large censoring rate. The computed out-of-control ARL, i.e., $\mathrm{ARL}_{1}$ values assuming $\mathrm{ARL}_{0}=200$ and $n=3$ and $n=7$, are given in Tables 3-6. Further, $20 \%$ and $30 \%$ increase and decrease in the mean levels have been used as shifts in the computation. One can obtain similar results for other values of $n, P_{c}, C$, and $\mathrm{ARL}_{0}$ by using Algorithm 1. Similarly, the algorithm can be used to obtain UCL and $\mathrm{ARL}_{1}$ results for other charts as discussed in this study.

For the out-of-control ARL computation, introduce a shift in the data and test it against the control limit constructed using in-control data. Repeat Steps 4 and 5 and calculate the average of subgroups falling outside the UCL, which is $\mathrm{ARL}_{1}$. Note that in some cases, it may happen that no subgroup monitoring statistic falls outside the UCL. To fix this issue, one can ignore the iteration of that particular index.

4.1. Estimation Effect on ARL. To evaluate the effect of estimation on ARL, one can notice from Table 3 that the CMHDEWMA chart outperforms the CM-DEWMA chart. Furthermore, comparing the results of Tables 3 and 4, the ARL values for the known parameter are noticed to be smaller than the estimated parameter case. Hence, the effect of estimation on the CM-HDEWMA is noticed as significant as in the case of other charts. In the case of a decreasing shift, the ARL value decreased with the increase of censoring rate and vice versa. To be more specific, consider the case of $20 \%$ censoring rate in Table 3 . In this case, one can see that for $30 \%$ increasing shift, $\mathrm{ARL}_{1}$ is 10 for the CM-DEWMA chart while ARL is 7.69 for the CM-HDEWMA chart. Similarly, for $30 \%$ censoring rates, $\mathrm{ARL}_{1}=12.35$ for CM-DEWMA chart and 11.90 for CM-HDEWMA chart, and a similar
TABle 2: $\mathrm{UCL}_{\mathrm{CMHDEWMA}}$ values $(\beta=0.5)$.

\begin{tabular}{ccccc}
\hline \multicolumn{3}{c}{$n=3}$, & \multicolumn{2}{c}{$n=7}$, \\
$P_{c}$ & \multicolumn{2}{c}{$\lambda_{1}=\lambda_{2}=0.2, \lambda_{3}=0.3$} & \multicolumn{2}{c}{$\lambda_{1}=\lambda_{2}=0.2, \lambda_{3}=0.3$} \\
& Known parameter & MLE & Known parameter & MLE \\
\hline 0.2 & 1.58 & 1.63 & 1.44 & 1.51 \\
0.3 & 1.68 & 1.82 & 1.52 & 1.64 \\
0.5 & 1.96 & 2.15 & 1.88 & 1.95 \\
0.6 & 2.11 & 2.40 & 1.94 & 2.24 \\
\hline
\end{tabular}

pattern is observed for other censoring rates and shifts (increased/decreased). Therefore, we can conclude that the proposed CM-HDEWMA chart outperforms the CMDEWMA chart. Furthermore, on comparing the results of Tables 3 and 4, if the parameter is known, the $\mathrm{ARL}_{1}$ value is 7.69 for the CM-HDEWMA chart for $30 \%$ increasing shift in the mean with $20 \%$ censoring rate. On the contrary, if the parameter is estimated, the $\mathrm{ARL}_{1}$ value for the aforementioned specifications is 9.03. A very similar pattern is also observed for other choices of shifts and censoring rates. Thus, for the known parameter case, the $\mathrm{ARL}_{1}$ values are smaller than the estimated parameter case. It is also observed that the impact of estimation on the CM-HDEWMA is as significant as noticed in other charts. Thus, it can be concluded that for a decreasing shift, the ARL value decreased with the increase of censoring rate, whereas an opposite behavior is noticed for an increasing shift.

Next, from Table 4, it can be seen that for 30\% increasing shift in the mean, the $\mathrm{ARL}_{1}$ value for CM-HDEWMA chart using the censoring rate $20 \%$ is 7.69 , while it is 11.90 and 22.40 for $30 \%$ and $40 \%$ censoring rates, respectively. Contrary to increasing shifts, for $30 \%$ decreasing shift, the $\mathrm{ARL}_{1}$ value corresponding to the censoring rate $20 \%$ is 3.95 , while it is 4.34 and 2.53 for $30 \%$ and $40 \%$ censoring rates respectively. It is also noticed that the superiority of the CMHDEWMA chart is never compromised. Similarly, the other results presented in the tables can be interpreted.

For $\alpha=1$ and $n=7$, the computed ARL is given in Table 5. These results are also compared with the estimated 
TABLe 3: Out-of-control ARL values for CM-HDEWMA and CM-DEWMA control charts for $n=3$ and $\alpha=0.5, \beta=0.5$.

\begin{tabular}{|c|c|c|c|c|c|c|c|c|c|}
\hline \multirow{3}{*}{$\begin{array}{l}n \\
\lambda_{1}=\lambda_{2}=0.2\end{array}$} & \multicolumn{9}{|c|}{3} \\
\hline & \multicolumn{4}{|c|}{ CM-DEWMA chart shifts } & \multirow{2}{*}{$\begin{array}{l}\lambda_{1}=\lambda_{2}=0.2 \\
\lambda_{3}=0.3\end{array}$} & \multicolumn{4}{|c|}{ CM-HDEWMA chart shifts } \\
\hline & $\begin{array}{c}30 \% \\
\text { increase }\end{array}$ & $\begin{array}{c}30 \% \\
\text { decrease }\end{array}$ & $\begin{array}{c}20 \% \\
\text { increase }\end{array}$ & $\begin{array}{c}20 \% \\
\text { decrease }\end{array}$ & & $\begin{array}{c}30 \% \\
\text { increase }\end{array}$ & $\begin{array}{c}30 \% \\
\text { decrease }\end{array}$ & $\begin{array}{c}20 \% \\
\text { increase }\end{array}$ & $\begin{array}{c}20 \% \\
\text { decrease }\end{array}$ \\
\hline Pc & & \multicolumn{2}{|c|}{ Shifts } & \multicolumn{2}{|r|}{ Pc } & \multicolumn{4}{|c|}{ Shifts } \\
\hline \multirow{3}{*}{$\mathrm{ARL}_{0}=200$} & 10.44 & 5.98 & 13.77 & 13.37 & \multirow{3}{*}{$\mathrm{ARL}_{0}=200$} & 7.69 & 3.95 & 11.91 & 11.84 \\
\hline & 12.35 & 5.00 & 25.54 & 14.84 & & 11.90 & 4.34 & 24.15 & 11.87 \\
\hline & 23.56 & 4.84 & 50.09 & 9.50 & & 22.40 & 2.53 & 48.09 & 7.12 \\
\hline
\end{tabular}

TABLE 4: Out-of-control ARL values for CM-HDEWMA and CM-DEWMA control charts for $n=3$ with MLE $\widehat{\alpha}=0.475, \beta=0.5$.

\begin{tabular}{|c|c|c|c|c|c|c|c|c|c|}
\hline \multirow{3}{*}{$\begin{array}{l}n \\
\lambda_{1}=\lambda_{2}=0.2\end{array}$} & \multicolumn{9}{|c|}{3} \\
\hline & \multicolumn{4}{|c|}{ CM-DEWMA chart shifts } & \multirow{2}{*}{$\begin{array}{l}\lambda_{1}=\lambda_{2}=0.2 \\
\lambda_{3}=0.3\end{array}$} & \multicolumn{4}{|c|}{ CM-HDEWMA chart shifts } \\
\hline & $\begin{array}{c}30 \% \\
\text { increase }\end{array}$ & $\begin{array}{c}30 \% \\
\text { decrease }\end{array}$ & $\begin{array}{c}20 \% \\
\text { increase }\end{array}$ & $\begin{array}{c}20 \% \\
\text { decrease }\end{array}$ & & $\begin{array}{c}30 \% \\
\text { increase }\end{array}$ & $\begin{array}{c}30 \% \\
\text { decrease }\end{array}$ & $\begin{array}{c}20 \% \\
\text { increase }\end{array}$ & $\begin{array}{c}20 \% \\
\text { decrease }\end{array}$ \\
\hline$\overline{P c}$ & & \multicolumn{2}{|c|}{ Shifts } & \multicolumn{2}{|r|}{ Pc } & \multicolumn{4}{|c|}{ Shifts } \\
\hline \multirow{3}{*}{$\mathrm{ARL}_{0}=200$} & 11.09 & 6.00 & 17.02 & 15.18 & \multirow{3}{*}{$\mathrm{ARL}_{0}=200$} & 9.03 & 6.76 & 11.71 & 13.47 \\
\hline & 12.76 & 4.72 & 27.98 & 15.04 & & 12.47 & 4.61 & 25.71 & 11.53 \\
\hline & 23.96 & 4.68 & 49.45 & 10.20 & & 23.26 & 2.25 & 51.72 & 7.40 \\
\hline
\end{tabular}

TABle 5: Out-of-control ARL values for CM-HDEWMA and CM-DEWMA control charts for $n=7$ with $\alpha=1, \beta=0.75$.

\begin{tabular}{|c|c|c|c|c|c|c|c|c|c|}
\hline \multirow{3}{*}{$\begin{array}{l}n \\
\lambda_{1}=\lambda_{2}=0.2\end{array}$} & \multicolumn{9}{|c|}{7} \\
\hline & \multicolumn{4}{|c|}{ CM-DEWMA chart shifts } & \multirow{2}{*}{$\begin{array}{l}\lambda_{1}=\lambda_{2}=0.2 \\
\lambda_{3}=0.3\end{array}$} & \multicolumn{4}{|c|}{ CM-HDEWMA chart shifts } \\
\hline & $\begin{array}{c}30 \% \\
\text { increase }\end{array}$ & $\begin{array}{c}30 \% \\
\text { decrease }\end{array}$ & $\begin{array}{c}20 \% \\
\text { increase }\end{array}$ & $\begin{array}{c}20 \% \\
\text { decrease }\end{array}$ & & $\begin{array}{c}30 \% \\
\text { increase }\end{array}$ & $\begin{array}{c}30 \% \\
\text { decrease }\end{array}$ & $\begin{array}{c}20 \% \\
\text { increase }\end{array}$ & $\begin{array}{c}20 \% \\
\text { decrease }\end{array}$ \\
\hline $\mathrm{Pc}$ & & \multicolumn{2}{|c|}{ Shifts } & \multicolumn{2}{|r|}{$\mathrm{Pc}$} & \multicolumn{4}{|c|}{ Shifts } \\
\hline \multirow{3}{*}{$\begin{array}{l}0.2 \\
0.3 \\
0.4\end{array} \mathrm{ARL}_{0}=200$} & 7.98 & 5.59 & 11.83 & 11.56 & \multirow{3}{*}{$\mathrm{ARL}_{0}=200$} & 7.13 & 4.41 & 11.49 & 10.94 \\
\hline & 11.82 & 4.13 & 26.43 & 10.99 & & 9.33 & 3.68 & 22.59 & 9.82 \\
\hline & 22.92 & 4.03 & 47.83 & 8.26 & & 22.33 & 2.11 & 45.59 & 6.82 \\
\hline
\end{tabular}

TABLE 6: Out-of-control ARL values for CM-HDEWMA and CM-DEWMA control charts for $n=3$ with MLE $\bar{\alpha}=0.91, \beta=0.75$.

\begin{tabular}{|c|c|c|c|c|c|c|c|c|c|}
\hline \multirow{3}{*}{$\begin{array}{l}n \\
\lambda_{1}=\lambda_{2}=0.2\end{array}$} & \multicolumn{9}{|c|}{7} \\
\hline & \multicolumn{4}{|c|}{ CM-DEWMA chart shifts } & \multirow[b]{2}{*}{$\begin{array}{l}\lambda_{1}=\lambda_{2}=0.2 \\
\lambda_{3}=0.3\end{array}$} & \multicolumn{4}{|c|}{ CM-HDEWMA chart shifts } \\
\hline & $\begin{array}{c}30 \% \\
\text { increase }\end{array}$ & $\begin{array}{c}30 \% \\
\text { decrease }\end{array}$ & $\begin{array}{c}20 \% \\
\text { increase }\end{array}$ & $\begin{array}{c}20 \% \\
\text { decrease }\end{array}$ & & $\begin{array}{c}30 \% \\
\text { increase }\end{array}$ & $\begin{array}{c}30 \% \\
\text { decrease }\end{array}$ & $\begin{array}{c}20 \% \\
\text { increase }\end{array}$ & $\begin{array}{c}20 \% \\
\text { decrease }\end{array}$ \\
\hline Pc & & \multicolumn{2}{|c|}{ Shifts } & \multicolumn{2}{|r|}{ Pc } & \multicolumn{4}{|c|}{ Shifts } \\
\hline \multirow{3}{*}{$\mathrm{ARL}_{0}=200$} & 8.65 & 5.87 & 12.83 & 12.21 & \multirow{3}{*}{$\mathrm{ARL}_{0}=200$} & 7.95 & 4.86 & 11.60 & 11.80 \\
\hline & 12.46 & 4.41 & 27.16 & 11.54 & & 10.19 & 4.13 & 23.55 & 9.95 \\
\hline & 23.89 & 4.13 & 48.61 & 9.11 & & 22.75 & 2.74 & 45.83 & 7.51 \\
\hline
\end{tabular}

parameter case which are tabulated in Table 6. From the table, observe that for $30 \%$ upward shift in the mean assuming $20 \%$ censoring rate, the $\mathrm{ARL}_{1}$ value for CMDEWMA chart is 7.98, while it is 7.13 for CM-HDEWMA chart. In the case of $30 \%$ censoring rate, the value for $A R L_{1}$ is 11.82 for the CM-DEWMA chart and 9.33 for the CMHDEWMA chart. Thus, from the pattern, one can conclude that the CM-HDEWMA chart is more efficient than the CMDEWMA chart.

Moreover, comparing the results of Tables 5 and 6 and when the parameter is known/specified, the $\mathrm{ARL}_{1}$ value for CM-HDEWMA chart for $30 \%$ increase in the mean level with $20 \%$ censoring rates is 7.13 . However, for the estimated case, it is 7.95 for the aforementioned specification. This also points out the impact of estimation on the CM-HDEWMA is highly significant as it is noticed in the case of other charts [22].

From Tables 7 and 8 , for the estimated $\bar{\alpha}=0.91$ and $\beta=$ 1.5 case, one can see that the ARL for the known parameter is smaller than that for the estimated case. For a decreasing shift, the ARL values decrease with the increase of censoring rate, whereas an opposite behavior is noticed in the case of increasing shifts. Thus, the superiority of the CMHDEWMA chart is clearly visible. 
(1) Initiate the algorithm by fixing $n, P_{c}$, and group size. Estimate the parameter using phase-I data if it is unknown.

(2) Replace the censored observations with the CM value, i.e., transform the data into $G_{i j}$ and compute the CM-HDEWMA statistics for given $m$ and $n$. Take the $(1-p)$ th quantile point, where $p$ is prespecified.

(3) Repeat Step $2 w$ times and compute the average of the upper control limits obtained by taking the $(1-p)$ th quantile of the monitoring statistic, which will result in UCL for the CM-HDEWMA chart.

(4) Plot the values of CM-HDEWMA monitoring statistic with respect to the subgroup numbers. Record the sample number at which the monitoring statistic falls outside the control limit.

(5) Repeat Step 4 a large number of times and calculate the mean of the subgroup numbers at which the process first time crossed the UCL. This will result in $\mathrm{ARL}_{0}$ if the subgroups are generated from the in-control process.

Algorithm 1: $\mathrm{ARL}_{0}$ computation for HDEWMA.

TABLe 7: Out-of-control ARL values for CM-HDEWMA and CM-DEWMA control charts for $n=5$ and $\alpha=1, \beta=1.5$

\begin{tabular}{|c|c|c|c|c|c|c|c|c|c|}
\hline \multirow{3}{*}{$\begin{array}{l}n \\
\lambda_{1}=\lambda_{2}=0.2\end{array}$} & \multicolumn{9}{|c|}{5} \\
\hline & \multicolumn{4}{|c|}{ CM-DEWMA chart shifts } & \multirow{2}{*}{$\begin{array}{l}\lambda_{1}=\lambda_{2}=0.2 \\
\lambda_{3}=0.3\end{array}$} & \multicolumn{4}{|c|}{ CM-HDEWMA chart shifts } \\
\hline & $\begin{array}{c}30 \% \\
\text { increase }\end{array}$ & $\begin{array}{c}30 \% \\
\text { decrease }\end{array}$ & $\begin{array}{c}20 \% \\
\text { increase }\end{array}$ & $\begin{array}{c}20 \% \\
\text { decrease }\end{array}$ & & $\begin{array}{c}30 \% \\
\text { increase }\end{array}$ & $\begin{array}{c}30 \% \\
\text { decrease }\end{array}$ & $\begin{array}{c}20 \% \\
\text { increase }\end{array}$ & $\begin{array}{c}20 \% \\
\text { decrease }\end{array}$ \\
\hline \multirow{4}{*}{$\mathrm{ARL}_{0}=200$} & \multicolumn{4}{|c|}{ Shifts } & $\mathrm{Pc}$ & Shifts & & & \\
\hline & 9.66 & 4.88 & 15.72 & 13.49 & \multirow{3}{*}{$\mathrm{ARL}_{0}=200$} & 7.41 & 4.38 & 11.67 & 11.77 \\
\hline & 11.16 & 4.41 & 26.88 & 13.17 & & 10.00 & 4.05 & 26.89 & 10.53 \\
\hline & 23.10 & 3.00 & 51.62 & 9.64 & & 21.45 & 1.76 & 49.14 & 6.06 \\
\hline
\end{tabular}

TABLE 8: Out-of-control ARL values for CM-HDEWMA and CM-DEWMA control charts for $n=5$ with MLE $\widehat{\alpha}=0.91, \beta=1.5$.

\begin{tabular}{|c|c|c|c|c|c|c|c|c|c|}
\hline \multirow{3}{*}{$\begin{array}{l}n \\
\lambda_{1}=\lambda_{2}=0.2 \\
\lambda_{3}=0.3\end{array}$} & \multicolumn{9}{|c|}{-} \\
\hline & \multicolumn{4}{|c|}{ CM-DEWMA chart shifts } & $=02$ & \multicolumn{4}{|c|}{ CM-HDEWMA chart shifts } \\
\hline & $\begin{array}{c}30 \% \\
\text { increase }\end{array}$ & $\begin{array}{c}30 \% \\
\text { decrease }\end{array}$ & $\begin{array}{c}20 \% \\
\text { increase }\end{array}$ & $\begin{array}{c}20 \% \\
\text { decrease }\end{array}$ & $\begin{array}{l}\lambda_{1}=\lambda_{2}- \\
\lambda_{3}=0.3\end{array}$ & $\begin{array}{c}30 \% \\
\text { increase }\end{array}$ & $\begin{array}{c}30 \% \\
\text { decrease }\end{array}$ & $\begin{array}{c}20 \% \\
\text { increase }\end{array}$ & $\begin{array}{c}20 \% \\
\text { decrease }\end{array}$ \\
\hline $\mathrm{Pc}$ & & \multicolumn{2}{|c|}{ Shifts } & \multicolumn{2}{|r|}{$\mathrm{Pc}$} & \multicolumn{4}{|c|}{ Shifts } \\
\hline \multirow{3}{*}{$\mathrm{ARL}_{0}=200$} & 10.42 & 5.49 & 16.83 & 14.62 & \multirow{3}{*}{$\mathrm{ARL}_{0}=200$} & 7.80 & 5.45 & 11.85 & 12.98 \\
\hline & 12.20 & 5.13 & 27.81 & 13.46 & & 11.01 & 4.40 & 27.24 & 11.17 \\
\hline & 23.90 & 3.65 & 52.30 & 9.98 & & 21.89 & 2.27 & 50.05 & 6.19 \\
\hline
\end{tabular}

Assuming $\alpha=1.5, \beta=2$ and $n=7$, results are listed in Table 9 and compared to the ARL in the estimated case (Table 10). Again, it is observed that CM-HDEWMA outperformed the CM-DEWMA chart for various shifts.

4.2. Effect of Smoothing Parameters. For the computed ARL values given in Tables 3-10, it is assumed that $\lambda_{1}=\lambda_{2}=0.2$, and $\lambda_{3}=0.3$. However, to evaluate the effect of the smoothing parameters on the CM-HDEWMA chart, we further assume the following two cases: (i) $\lambda_{1}<\lambda_{2}<\lambda_{3}$ and (ii) $\lambda_{1}>\lambda_{2}>\lambda_{3}$. The resulting ARL is listed in Tables 11 and 12. The tables suggest that the efficiency of the proposed chart increased when smoothed parameters are $\lambda_{1}>\lambda_{2}>\lambda_{3}$. It is worth mentioning that as the values of $\lambda_{1}, \lambda_{2}$, and $\lambda_{3}$ approach 1, the proposed chart converges to the Shewhart control chart. Further, for small values of $\lambda_{1}, \lambda_{2}$, and $\lambda_{3}$, the performance of the proposed chart is enhanced as compared to moderate or high values (close to 1 ) of smoothing parameters. When the smoothing parameter is in reverse order, i.e., case (ii), the proposed control chart shows the best performance (cf. Tables 11 and 12).

4.3. Effect of Estimation on $A R L_{0}$. To minimize the impact of estimation on the in-control and out-of-control ARL, the adjusted UCL values for different censoring rates are listed in Table 2. As the estimated ARL is a function of the sample and subgroup sizes, to study the effect of estimation and to have the prefixed in-control ARL with estimated parameter case, the results of ARL along with standard deviation for different $n$ and $m$ are tabulated in Table 13. From the table, it is clear that CM-HDEWMA approaches more quickly to the desired values of the ARL as compared to the CM-DEWMA chart. Furthermore, it is noticed that very large sample sizes and subgroup numbers are required to have the prefixed ARL in the presence of estimation effect. To be more specific, if $n=10$ and $m=1000$, the standard deviation of the run length (SDRL) is 21.42 for the CM-HDEWMA chart, which is still a very high value. Thus, in the case of estimation, one should 
TABLe 9: Out-of-control ARL Values for CM-HDEWMA and CM-DEWMA control charts for $n=7$ with $\alpha=1.5, \beta=2$.

\begin{tabular}{|c|c|c|c|c|c|c|c|c|c|}
\hline \multirow{3}{*}{$\begin{array}{l}n \\
\lambda_{1}=\lambda_{2}=0.2 \\
\lambda_{3}=0.3\end{array}$} & \multicolumn{9}{|c|}{7} \\
\hline & \multicolumn{4}{|c|}{ CM-DEWMA chart shifts } & \multirow{2}{*}{$\begin{array}{l}\lambda_{1}=\lambda_{2}=0.2 \\
\lambda_{3}=0.3\end{array}$} & \multicolumn{4}{|c|}{ CM-HDEWMA chart shifts } \\
\hline & $\begin{array}{c}30 \% \\
\text { increase }\end{array}$ & $\begin{array}{c}30 \% \\
\text { decrease }\end{array}$ & $\begin{array}{c}20 \% \\
\text { increase }\end{array}$ & $\begin{array}{c}20 \% \\
\text { decrease }\end{array}$ & & $\begin{array}{c}30 \% \\
\text { increase }\end{array}$ & $\begin{array}{c}30 \% \\
\text { decrease }\end{array}$ & $\begin{array}{c}20 \% \\
\text { increase }\end{array}$ & $\begin{array}{c}20 \% \\
\text { decrease }\end{array}$ \\
\hline Pc & & \multicolumn{2}{|c|}{ Shifts } & \multicolumn{2}{|r|}{$\mathrm{Pc}$} & \multicolumn{4}{|c|}{ Shifts } \\
\hline \multirow{3}{*}{$\mathrm{ARL}_{0}=200$} & 7.68 & 4.08 & 13.21 & 11.13 & \multirow{3}{*}{$\mathrm{ARL}_{0}=200$} & 6.66 & 3.80 & 10.72 & 8.25 \\
\hline & 10.92 & 3.96 & 25.96 & 10.30 & & 8.34 & 3.31 & 24.45 & 8.33 \\
\hline & 22.54 & 3.18 & 48.73 & 7.18 & & 20.47 & 1.46 & 44.94 & 7.07 \\
\hline
\end{tabular}

TABLe 10: Out-of-control ARL values for CM-HDEWMA and CM-DEWMA control charts for $n=7$ with MLE $\widehat{\alpha}=1.43, \beta=2$.

\begin{tabular}{|c|c|c|c|c|c|c|c|c|c|}
\hline \multirow{3}{*}{$\begin{array}{l}n \\
\lambda_{1}=\lambda_{2}=0.2 \\
\lambda_{3}=0.3\end{array}$} & \multicolumn{9}{|c|}{7} \\
\hline & \multicolumn{4}{|c|}{ CM-DEWMA chart shifts } & \multirow{2}{*}{$\begin{array}{l}\lambda_{1}=\lambda_{2}=0.2 \\
\lambda_{3}=0.3\end{array}$} & \multicolumn{4}{|c|}{ CM-HDEWMA chart shifts } \\
\hline & $\begin{array}{c}30 \% \\
\text { increase }\end{array}$ & $\begin{array}{c}30 \% \\
\text { decrease }\end{array}$ & $\begin{array}{c}20 \% \\
\text { increase }\end{array}$ & $\begin{array}{c}20 \% \\
\text { decrease }\end{array}$ & & $\begin{array}{c}30 \% \\
\text { increase }\end{array}$ & $\begin{array}{c}30 \% \\
\text { decrease }\end{array}$ & $\begin{array}{c}20 \% \\
\text { increase }\end{array}$ & $\begin{array}{c}20 \% \\
\text { decrease }\end{array}$ \\
\hline $\mathrm{Pc}$ & & \multicolumn{2}{|c|}{ Shifts } & \multicolumn{2}{|r|}{ Pc } & \multicolumn{4}{|c|}{ Shifts } \\
\hline \multirow{3}{*}{$\mathrm{ARL}_{0}=200$} & 8.02 & 4.87 & 14.26 & 11.69 & \multirow{3}{*}{$\mathrm{ARL}_{0}=200$} & 7.63 & 3.95 & 10.96 & 9.33 \\
\hline & 12.12 & 4.98 & 27.20 & 11.00 & & 8.54 & 4.10 & 25.35 & 8.71 \\
\hline & 23.27 & 3.21 & 49.16 & 7.87 & & 20.67 & 2.18 & 45.55 & 7.46 \\
\hline
\end{tabular}

TABLe 11: Out-of-control ARL values for CM-HDEWMA and CM-DEWMA control charts for $n=3$ with $\alpha=0.5, \beta=0.5$ for $\lambda_{1}<\lambda_{2}<\lambda_{3}$.

\begin{tabular}{|c|c|c|c|c|c|c|c|c|c|c|c|}
\hline \multirow[t]{3}{*}{$n$} & \multirow{3}{*}{$\begin{array}{l}\lambda_{1}=0.1 \\
\lambda_{2}=0.15 \\
\lambda_{3}=0.2\end{array}$} & \multicolumn{10}{|c|}{3} \\
\hline & & \multicolumn{4}{|c|}{ CM-DEWMA chart shifts } & \multirow{2}{*}{\multicolumn{2}{|c|}{$\begin{array}{l}\lambda_{1}=0.1 \\
\lambda_{2}=0.15 \\
\lambda_{3}=0.2\end{array}$}} & \multicolumn{4}{|c|}{ CM-HDEWMA chart shifts } \\
\hline & & $\begin{array}{c}30 \% \\
\text { increase }\end{array}$ & $\begin{array}{c}30 \% \\
\text { decrease }\end{array}$ & $\begin{array}{c}20 \% \\
\text { increase }\end{array}$ & $\begin{array}{c}20 \% \\
\text { decrease }\end{array}$ & & & $\begin{array}{c}30 \% \\
\text { increase }\end{array}$ & $\begin{array}{c}30 \% \\
\text { decrease }\end{array}$ & $\begin{array}{c}20 \% \\
\text { increase }\end{array}$ & $\begin{array}{c}20 \% \\
\text { decrease }\end{array}$ \\
\hline$\overline{P c}$ & \multirow{4}{*}{$\mathrm{ARL}_{0}=200$} & & \multicolumn{2}{|c|}{ Shifts } & \multicolumn{3}{|c|}{ Pc } & \multicolumn{4}{|c|}{ Shifts } \\
\hline 0.2 & & 8.18 & 4.07 & 14.94 & 12.05 & 0.2 & \multirow{3}{*}{$\mathrm{ARL}_{0}=200$} & 5.72 & 3.84 & 12.96 & 11.85 \\
\hline 0.3 & & 11.93 & 1.27 & 26.12 & 13.12 & 0.3 & & 10.78 & 1.81 & 25.70 & 8.49 \\
\hline 0.4 & & 23.15 & 1.66 & 49.65 & 10.01 & 0.4 & & 20.51 & 1.12 & 47.66 & 4.36 \\
\hline
\end{tabular}

TABle 12: Out-of-control ARL values for CM-HDEWMA and CM-DEWMA control charts for $n=3, \alpha=0.5, \beta=0.5$, and $\lambda_{1}>\lambda_{2}>\lambda_{3}$.

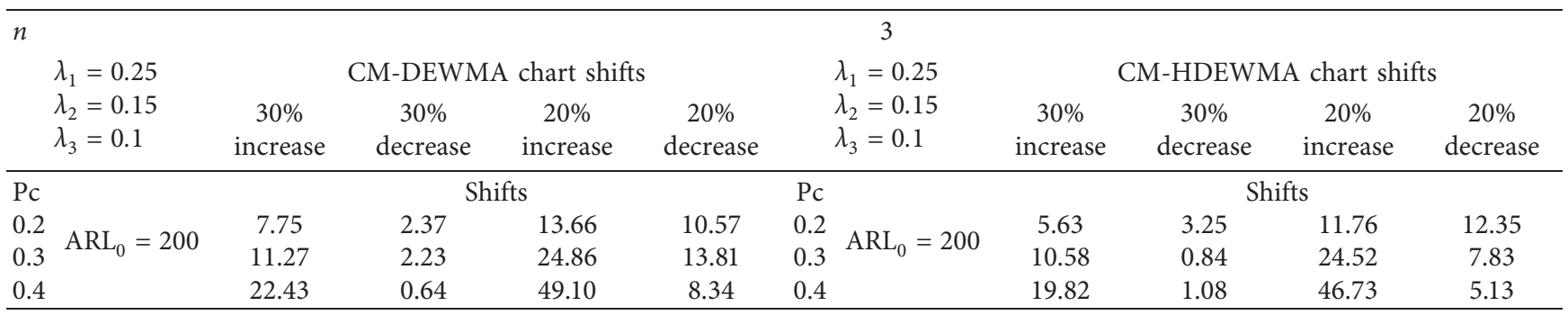

TABLE 13: Estimation effect on $\mathrm{ARL}_{0}$ at different values of $m$ and $n$ for CM-DEWMA and CM-HDEWMA control charts assuming $\bar{\alpha}=0.5, \beta=0.5, \lambda=0.15$, and $\mathrm{ARL}_{0}=200$.

\begin{tabular}{|c|c|c|c|c|c|c|c|c|}
\hline \multirow{4}{*}{$\begin{array}{l}m \\
n\end{array}$} & \multicolumn{5}{|c|}{ CM-DEWMA } & \multicolumn{3}{|c|}{ CM-HDEWMA } \\
\hline & \multicolumn{8}{|c|}{$P c=30 \%, \lambda=0.15$} \\
\hline & 100 & 500 & 700 & 1000 & 100 & 500 & 700 & 1000 \\
\hline & \multicolumn{8}{|c|}{$\mathrm{ARL}_{0}(\mathrm{SDRL})$} \\
\hline 3 & 171.71(39.99) & $173.25(38.18)$ & $177.35(37.27)$ & $177.46(35.95)$ & $178.08(37.79)$ & $180.45(37.66)$ & $185.11(35.22)$ & $188.7(33.89)$ \\
\hline 5 & $173.99(35.54)$ & $175.55(31.87)$ & $178.35(30.9)$ & 181.61(32.09) & $183.59(33.56)$ & $185.26(32.33)$ & $191.93(31.94)$ & $195.25(32.09)$ \\
\hline 7 & $180.54(28.78)$ & $181.05(25.38)$ & $182.54(25.24)$ & $185.95(24.36)$ & $187.8(28.53)$ & $190.25(27.03)$ & $194.51(24.62)$ & $198.27(24.74)$ \\
\hline 10 & $189.01(23.81)$ & $189.78(22.42)$ & $191.08(20.69)$ & $194.87(20.75)$ & $188.84(22.56)$ & $193.26(20.09)$ & $195.58(20.27)$ & $200.47(21.42)$ \\
\hline
\end{tabular}




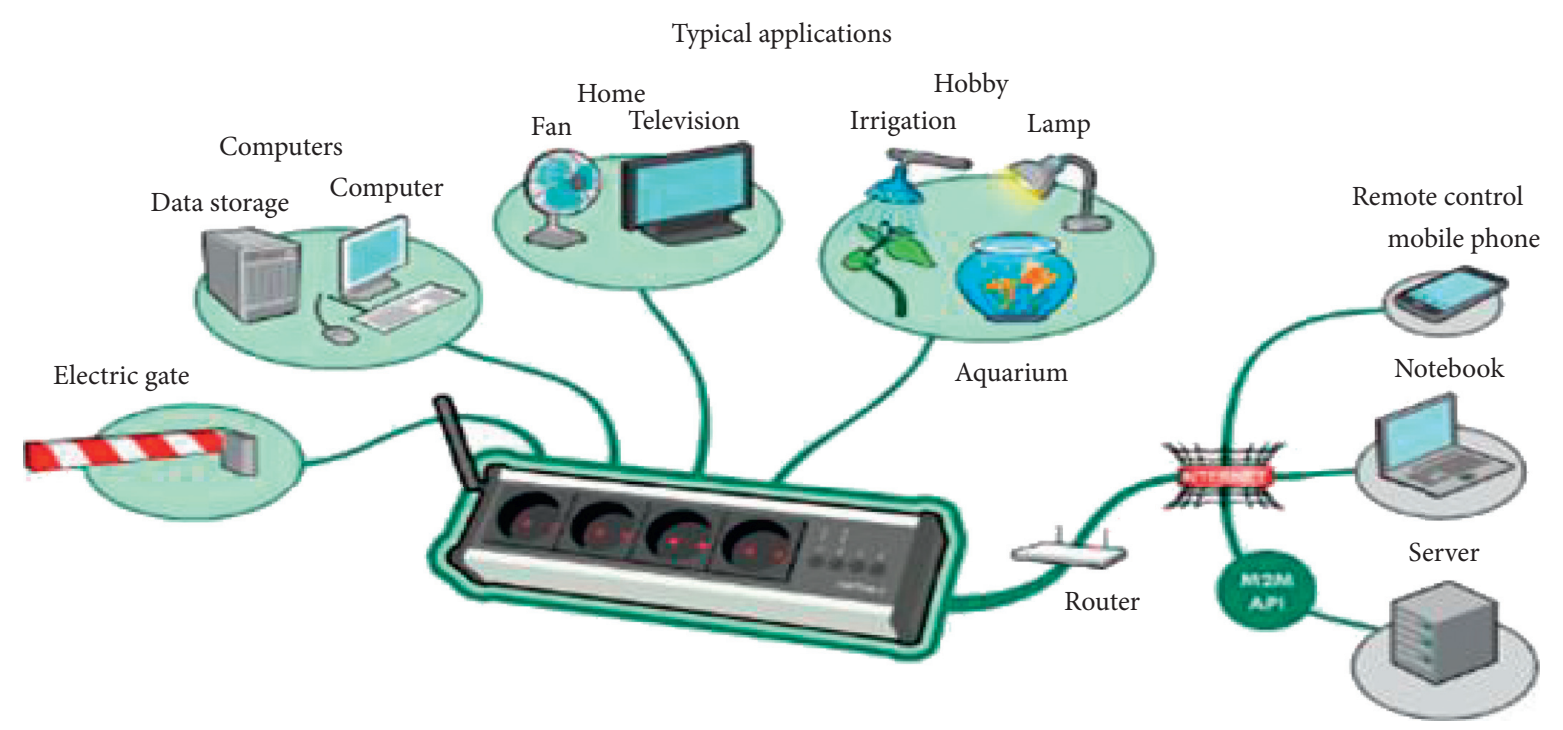

FIgURE 1: Application of electric sockets in real life.

be very careful in the interpretation of an out-of-control signal because of the large dispersion in the run length. below:

In short, a summary of the important findings is given

(i) For low censoring rate, an increasing shift in the scale parameter is more efficiently detected by the CM-HDEWMA chart as compared to a decreasing shift. Further, the effectiveness of the chart is not undermined to the CM-DEWMA chart for high censoring rate and decreasing shifts.

(ii) It is also noticed that the proposed chart is superior to its counterpart in both cases, increasing and decreasing shifts, in absolute terms. Moreover, the ARL follows the unbiasedness property, i.e., out-ofcontrol ARL never exceeds the $\mathrm{ARL}_{0}$ value.

(iii) As discussed in the literature for other charts, this study confirmed that the parameter estimation is strongly correlated to the chart performance. Thus, to overcome this estimation effect and to have the desired in-control ARL, a large sample size is recommended. Moreover, a special attention should be paid to the SDRL of the ARL.

(iv) The performance of the CM-HDEWMA chart can be improved by having a perfect ordering, i.e., $\lambda_{1}<\lambda_{2}<\lambda_{3}$ or $\lambda_{1}>\lambda_{2}>\lambda_{3}$, among the smoothing parameters.

\section{Application}

This section presents an application to show the implementation of the proposed methodology in practice. For this purpose, the socket dataset is taken from Wheeler [26] (page 150). This dataset is about the effective thickness of sockets using the injection molding, measured in hundreds of a millimeter by collecting four pieces at a time. Figure 1 shows the usage of electric sockets in different applications while Figure 2 shows the socket injection modeling machine.
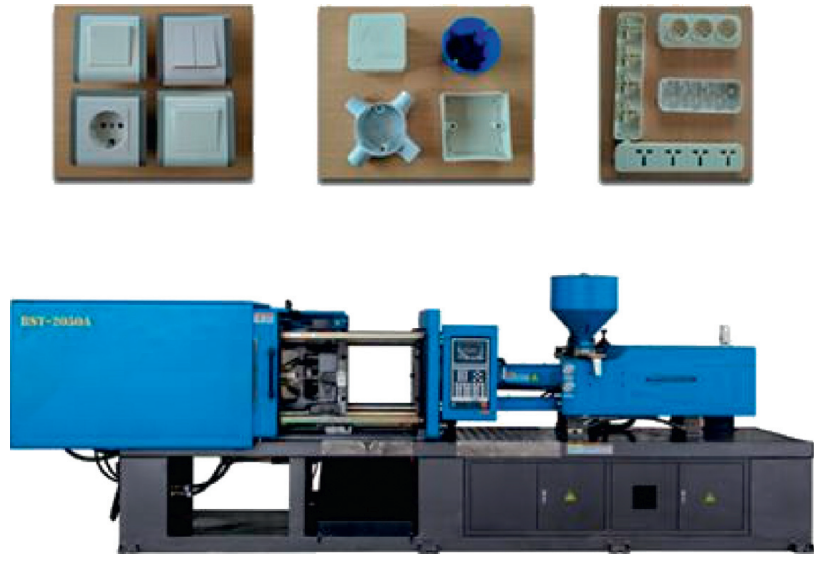

FIgURE 2: Socket injection modeling machine application.

For illustration, let the data follow the Weibull distribution with $\beta=0.5$. Since there is no information about the process parameters, we estimated the scale parameter $\bar{\alpha}=$ 1.61 assuming the first 45 observations as the phase-I data for $n=4$ of the Weibull distribution using the MLE. Furthermore, we considered $50 \%$ censoring rate to detect $25 \%$ decrease in the mean to implement the hybrid control chart.

From Figure 3, it is observed that the proposed and CMDEWMA control charts do not produce any out-of-control signal for the first 45 observations. To check the efficiency of the proposal, a dataset consisting of 35 observations is generated, i.e., after the $45^{\text {th }}$ subgroup. To generate the shifted data, a $25 \%$ decreasing shift in the mean of the Weibull distribution is introduced with censoring time 60.14 while $\mathrm{ARL}_{0}=45$. The $\mathrm{CM}$ value for the aforementioned specifications is 16.14 . For the shifted samples, the CMHDEWMA produced an out-of-control signal at the $3^{\text {rd }}$ sample while the CM-DEWMA control chart produced at the $7^{\text {th }}$ sample. Thus, the proposed chart is more efficient to detect an out-of-control situation than the ordinary CMDEWMA chart. 


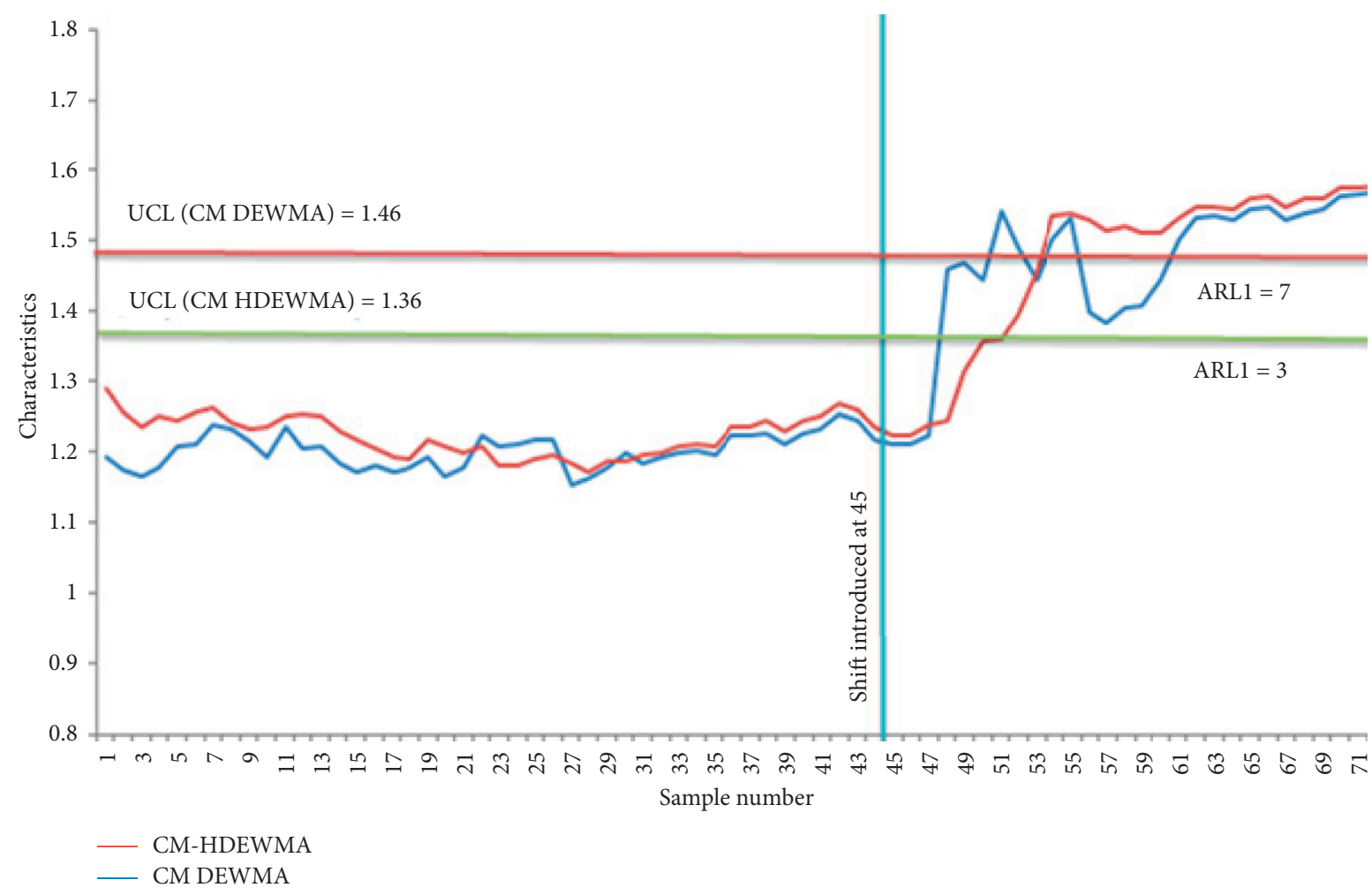

FIgURE 3: A comparison of CM-DEWMA and CM-HDEWMA charts using 25\% decrease in the mean for the socket data.

\section{Conclusion}

This article introduces a CM-based hybrid DEWMA chart, and its performance is evaluated in detail including a comparison with the CM-based DEWMA for monitoring the mean of the Weibull process in the presence of type-I censoring. Also, the performance of the control charts is not only assessed for the known parameter case but also for the unknown parameter case using the method of maximum likelihood estimation. The average run length is used to assess the performance of the charts. From the ARL study, it is noticed that the CM-HDEWMA chart outperformed the CM-DEWMA chart. Further, it is noticed that the impact of estimation is very serious on the ARL and a very large sample size is required to obtain the desired ARL. Moreover, one should be very careful about the dispersion in the run length which could be significantly larger than the nominal case. In future, the proposed methodology can be extended to other distributions and Shewhart control charts can be introduced [27]. Furthermore, a detailed study is required to evaluate the impact of parameter estimation on the censored hybrid double exponentially weighted moving average chart.

\section{Data Availability}

The data used to support the findings of this study are available from the corresponding author upon request.

\section{Conflicts of Interest}

The authors declare that they have no conflicts of interest.

\section{Acknowledgments}

This study was supported by the program of Shandong Province Natural Science Foundation of China (ZR2018BC012).

\section{References}

[1] S. H. Steiner and R. J. Mackay, "Monitoring processes with highly censored data," Journal of Quality Technology, vol. 32, no. 3, pp. 199-208, 2000.

[2] J. F. Lawless, Statistical Models and Methods for Lifetime Data, John Wiley \& Sons, New York, NY, USA, 2nd edition, 1982.

[3] Z. Li and Z. Kong, "A generalized procedure for monitoring right-censored failure time data," Quality and Reliability Engineering International, vol. 31, no. 4, pp. 695-705, 2015.

[4] S. Steiner and R. J. Mackay, "Detecting changes in the mean from censored lifetime data," Frontiers in Statistical Quality Control 6, vol. 6, pp. 275-289, 2001.

[5] S. H. Steiner and R. J. Mackay, "Monitoring processes with data censored owing to competing risks by using exponentially weighted moving average control charts," Journal of the Royal Statistical Society: Series C (Applied Statistics), vol. 50, no. 3, pp. 293-302, 2001.

[6] L. Zhang and G. Chen, "EWMA charts for monitoring the mean of censored Weibull lifetimes," Journal of Quality Technology, vol. 36, no. 3, pp. 321-328, 2004.

[7] W. Lu and T. R. Tsai, "Exponentially weighted moving average control chart for gamma distribution with type I censoring," in Proceedings of the 3rd International Conference on Innovative Computing Information and Control (ICICIC '08), Liaoning, China, June 2008. 
[8] T. R. Tsai and C. C. Lin, "The design of EWMA control chart for average with type-I censored data," International Journal of Quality \& Reliability Management, vol. 26, no. 4, pp. 397-405, 2009.

[9] S. M. M. Raza, M. Riaz, and S. Ali, "On the performance of EWMA and DEWMA control charts for censored data," Journal of the Chinese Institute of Engineers, vol. 38, no. 6, pp. 714-722, 2015.

[10] S. M. M. Raza, M. Riaz, and S. Ali, "EWMA control chart for Poisson-exponential lifetime distribution under type I censoring," Quality and Reliability Engineering International, vol. 32, no. 3, pp. 995-1005, 2016.

[11] C. Zhang, F. Tsung, and D. Xiang, "Monitoring censored lifetime data with a weighted-likelihood scheme," Naval Research Logistics (NRL), vol. 63, no. 8, pp. 631-646, 2016.

[12] S. M. M. Raza and A. F. Siddiqi, "EWMA and DEWMA control charts for Poisson-exponential distribution: conditional median approach for censored data," Quality and Reliability Engineering International, vol. 33, no. 2, pp. 387399, 2017.

[13] B. Guo and B. X. Wang, "Control charts for monitoring the Weibull shape parameter based on type-II censored sample," Quality and Reliability Engineering International, vol. 30, no. 1, pp. 13-24, 2014.

[14] S. Huang, J. Yang, and M. Xie, "A study of control chart for monitoring exponentially distributed characteristics based on type-II censored samples," Quality and Reliability Engineering International, vol. 33, no. 7, pp. 1513-1526, 2017.

[15] F. Pascual and S. Li, "Monitoring the Weibull shape parameter by control charts for the sample range of type II censored data," Quality and Reliability Engineering International, vol. 28, no. 2, pp. 233-246, 2012.

[16] J. A. Sterne, I. R. White, J. B. Carlin et al., "Multiple imputations for missing data in epidemiological and clinical research: potential and pitfalls," BMJ, vol. 338, 2009.

[17] C. Fuchs and R. S. Kenett, "Missing data and imputation," in Wiley Stats Ref: Statistics Reference Online, N. Balakrishnan, T. Colton, B. Everitt, W. Piegorsch, F. Ruggeri, and J. L. Teugels, Eds., Wiley, Hoboken, NJ, USA, 2014.

[18] P. Schmitt, J. Mandel, and M. Guedj, "A comparison of six methods for missing data imputation," Journal of Biometrics \& Biostatistics, vol. 6, no. 1, pp. 1-6, 2015.

[19] M. Azam, M. Aslam, and C.-H. Jun, "Designing of a hybrid exponentially weighted moving average control chart using repetitive sampling," The International Journal of Advanced Manufacturing Technology, vol. 77, no. 9-12, pp. 1927-1933, 2015.

[20] M. Aslam, N. Khan, and C.-H. Jun, "A hybrid exponentially weighted moving average chart for COM-Poisson distribution," Transactions of the Institute of Measurement and Control, vol. 40, no. 2, pp. 456-461, 2018.

[21] B. Laungrungrong, B. Mobasher, D. Montgomery, and C. M. Borror, "Hybrid control charts for active control and monitoring of concrete strength," Journal of Materials in Civil Engineering, vol. 22, no. 1, pp. 77-87, 2009.

[22] S. Ali, "Time-between-events control charts for an exponentiated class of distributions of the renewal process," Quality and Reliability Engineering International, vol. 33, no. 8, pp. 2625-2651, 2017.

[23] S. W. Roberts, "Control chart tests based on geometric moving averages," Technometrics, vol. 1, no. 3, pp. 239-250, 1959.

[24] A. S. Polunchenko, G. Sokolov, and A. G. Tartakovsky, "Optimal design and analysis of the Exponentially Weighted
Moving Average chart for exponential data," Sri Lankan Journal of Applied Statistics, vol. 5, no. 4, pp. 55-82, 2013.

[25] S. M. M. Raza, S. Ali, and M. M. Butt, "DEWMA control charts for censored data using Rayleigh lifetimes," Quality and Reliability Engineering International, vol. 34, no. 8, pp. 1675-1684, 2018.

[26] D. J. Wheeler, Advanced Topics in Statistical Process Control: The Power of Shewhart's Charts, PC Press, Knoxville, TN, USA, 1995.

[27] S. M. M. Raza, M. M. Lingua::EN::Titlecase, M. Moeen, and fnm Lingua::EN::Titlecase, "Modified Shewhart control chart based on CEV for gamma distributed lifetimes in the presence of type-I censored data," Journal of Quantitative Methods, vol. 2, no. 1, pp. 114-125, 2018. 